\title{
NCCAM/NCI Phase 1 Study of Mistletoe Extract and Gemcitabine in Patients with Advanced Solid Tumors
}

\author{
Patrick J. Mansky, ${ }^{1,2}$ Dawn B. Wallerstedt, ${ }^{3}$ Timothy S. Sannes, ${ }^{4}$ \\ Jamie Stagl, ${ }^{5}$ Laura Lee Johnson, ${ }^{2}$ Marc R. Blackman, ${ }^{6}$ Jean L. Grem, \\ Sandra M. Swain, ${ }^{8}$ and Brian P. Monahan' \\ ${ }^{1}$ The Cancer Team at Bellin Health, 1580 Commanche Avenue, Green Bay, WI 54313, USA \\ ${ }^{2}$ National Center for Complementary and Alternative Medicine, NIH, Bethesda, MD, USA \\ ${ }^{3}$ Samuelli Institute, Alexandria, VA, USA \\ ${ }^{4}$ Department of Clinical and Health Psychology, University of Florida, Gainesville, FL, USA \\ ${ }^{5}$ University of Miami, Miami, FL, USA \\ ${ }^{6}$ Research Service (151), Veterans Affairs Medical Center, and Department of Medicine, Georgetown University School of Medicine, \\ Washington, DC, USA \\ ${ }^{7}$ University of Nebraska Medical Center, Omaha, NE, USA \\ ${ }^{8}$ Washington Cancer Institute, Washington Hospital Center, Washington, DC, USA \\ ${ }^{9}$ Department of Medicine, Hematology and Medical Oncology Division, Uniformed Services University of the Health Sciences, \\ Bethesda, MD, USA
}

Correspondence should be addressed to Patrick J. Mansky; manpaj@bellin.org

Received 14 April 2013; Revised 23 July 2013; Accepted 17 September 2013

Academic Editor: Gunver Kienle

Copyright (C 2013 Patrick J. Mansky et al. This is an open access article distributed under the Creative Commons Attribution License, which permits unrestricted use, distribution, and reproduction in any medium, provided the original work is properly cited.

\begin{abstract}
Purpose. European Mistletoe (Viscum album L.) extracts (mistletoe) are commonly used for cancer treatment in Europe. This phase I study of gemcitabine (GEM) and mistletoe in advanced solid cancers (ASC) evaluated: (1) safety, toxicity, and maximum tolerated dose (MTD), (2) absolute neutrophil count (ANC) recovery, (3) formation of mistletoe lectin antibodies (ML ab), (4) cytokine plasma concentrations, (5) clinical response, and (6) pharmacokinetics of GEM. Methods. Design: increasing mistletoe and fixed GEM dose in stage I and increasing doses of GEM with a fixed dose of mistletoe in stage II. Dose limiting toxicities (DLT) were grade (G) 3 nonhematologic and G4 hematologic events; MTD was reached with 2 DLTs in one dosage level. Response in stage IV ASC was assessed with descriptive statistics. Statistical analyses examined clinical response/survival and ANC recovery. Results. DLTs were G4 neutropenia, G4 thrombocytopenia, G4 acute renal failure, and G3 cellulitis, attributed to mistletoe. GEM $1380 \mathrm{mg} / \mathrm{m}^{2}$ and mistletoe $250 \mathrm{mg}$ combined were the MTD. Of 44 patients, 24 developed nonneutropenic fever and flu-like syndrome. GEM pharmacokinetics were unaffected by mistletoe. All patients developed ML3 IgG antibodies. ANC showed a trend to increase between baseline and cycle 2 in stage I dose escalation. $6 \%$ of patients showed partial response, $42 \%$ stable disease. Median survival was 200 days. Compliance with mistletoe injections was high. Conclusion. GEM plus mistletoe is well tolerated. No botanical/drug interactions were observed. Clinical response is similar to GEM alone.
\end{abstract}

\section{Introduction}

European mistletoe (Viscum album L.), a semiparasitic plant growing on various trees [1], has been used in folklore and as a medicinal plant for several thousand years. In the modern era, it was first introduced as a plant extract preparation for the treatment of malignant diseases by Steiner [2]. A number of studies have reported immunostimulatory effects of mistletoe extracts, on mononuclear cells [3], lymphocytes [4-6], macrophages [7], and NK cells [8,9]. Mistletoe extracts contain a number of biologically active components, including mistletoe lectins (reviewed in [10-16]) and viscotoxins $[17,18]$. Mistletoe extracts may also have antiangiogenic properties [1]. Mistletoe lectins stimulate secretion of 
a number of cytokines including IL-6, IL-12, IL-1, and TNF$\alpha$ [19-21], may enhance cytotoxic NK-cell activity, and may induced apoptosis [22] and induction of FAS ligand [23]. Some of these findings have been supported by microarray gene expression profiling [24]. Mistletoe extract reduces leukopenia in chemotherapy-treated mice and stimulates neutropoiesis in mice after cyclophosphamide chemotherapy [25]. In a dose-dependent fashion, ML-1 may upregulate protein synthesis in neutrophils at low doses, while high doses resulted in neutrophil apoptosis via a caspase-dependent mechanism [26]. Mixed findings have been reported on mistletoe antibody formation. In vivo antibody formation has a protective effect against the toxicity of mistletoe lectins to normal somatic cells [27]. While ML antibodies were absent in patients without adverse effects [28], a potential role of MLantibodies in the neutralization of mistletoe lectin activity in vivo has been debated $[27,29]$. Collectively, the mounting preclinical data with mistletoe therapy suggests that rigorous clinical trials are needed.

In a phase I study in HIV-positive patients treated with Viscum album Quercus Frischsaft (QuFrF) [30], limited toxicities included flu-like symptoms, gingivitis, eosinophilia, and a slight rise in serum urea nitrogen and creatinine. Natural mistletoe lectins were detected in normal volunteers 2 weeks after single dose injection. Fever and flu-like symptoms were observed [31]. Thus, mistletoe preparations appear to be well tolerated, and antibody response appears to be robust. However, the clinical efficacy of mistletoe in oncology settings remains unclear. Notably, in a large retrospective study of mistletoe therapy in nonmetastatic breast cancer patients, fewer adverse events and longer survival were observed in the mistletoe therapy group compared to conventional therapy alone [32]. In a comparable retrospective study design in pancreatic cancer patients, similar clinical outcomes were observed with fewer adverse events and improved survival in patients treated with mistletoe [33]. Despite compelling preclinical data and these isolated reports of clinical benefit of mistletoe preparations, recent reviews of clinical trials still note methodological weaknesses of current published studies on mistletoe [34] as well as conflicting results on tumor response and survival prolongation on treatment using various mistletoe preparations [35-38]. A number of recently published studies confirm this mixed picture [39-42].

With converging preclinical evidence suggesting immunostimulatory and antiangiogenic properties of mistletoe, in addition to a dearth of well-designed clinical trials testing the safety and efficacy of mistletoe, the present study sought to administer mistletoe to advanced stage cancer patients, in combination with a standard, well-known chemotherapy regimen (GEM), hypothesizing that gemcitabine and mistletoe can be administered safely in combination to patients with advanced cancer. The study aims were to evaluate the following: (1) safety, toxicity, and maximum tolerated dose (MTD) of the mistletoe/GEM combination in patients with advanced solid cancers (ASC), (2) neutrophil count recovery, (3) formation of mistletoe lectin antibodies (ML ab), (4) cytokine plasma concentrations, (5) clinical response, and (6) GEM pharmacokinetics as an indicator of possible interactions of the mistletoe/GEM combination regimen.

\section{Materials and Methods}

2.1. Mistletoe Extract Quality and Content Verification. A whole plant mistletoe extract (HELIXOR Apis (A), growing on fir trees), Lot 021224 and Lot 0406, was used and supplied by Helixor, GmbH, Rosenfeld, Germany. Study agent content analyses was performed by the manufacturer. Product content verification analyses were conducted by Lawrence Livermore National Laboratories, Livermore, CA, USA. Verification analyses were consistent with the manufacturer's analyses and showed no evidence for product contamination with pesticides, heavy metals, or the prescription drugs listed. The Helixor mistletoe extract was assayed for approximately 60 elemental species by inductively-coupled-plasma/mass spectrometry (ICP-MS). In addition, Helixor A mistletoe extract was assayed for a variety of pesticides and street drugs including stimulants, narcotics, and tranquilizers using gas chromatography-mass spectroscopy GC-MS.

Liquid Chromatography-Mass Spectrometry (LC-MS and LC-MS/MS) analysis of Helixor mistletoe formulation for commonly used oncology drugs was negative. Helixor A mistletoe extract was assayed by thin-layer chromatography (TLC) via a QA/QC protocol supplied by Helixor. TLC assay results of the submitted Helixor solution were very similar to those expected from the Helixor QA/QC protocol.

Both lots were tested in parallel up to this final assay performed on 14 February 2006. Lot 021224 contained 3.4 $( \pm 0.2) \mathrm{ng} / \mathrm{mL}$ ML-I and $178( \pm 4) \mathrm{ng} / \mathrm{mL}$ ML-III. Lot 040686 contained $9.2( \pm 0.9) \mathrm{ng} / \mathrm{mL}$ ML-I and $293( \pm 12) \mathrm{ng} / \mathrm{mL}$ MLIII.

For the study, two lots of mistletoe were manufactured, as the period of study enrollment spanned more than 2 years. The initial mistletoe lot was tested for ML-I and ML-III stability at the beginning of the study, and at 6, 15, and 18 months. ML-I and ML-III concentrations remained stable for 2 years.

2.2. Patient Recruitment and Screening Statistics. The protocol, informed consent, and patient recruitment materials were reviewed and approved by the National Cancer Institute's Institutional Review Board (IRB) on July 15, 2002 and by the National Naval Medical Center's IRB on December 12, 2002 (study number 02-AT-0260). A total of 704 persons expressed interest in this study and were contacted over this five year study. Forty-four persons (6\%) were enrolled onstudy after meeting all study eligibility criteria and signing written informed consent.

2.3. Study Eligibility Criteria. Patients with histologically confirmed treated or untreated, advanced pancreatic or nonsmall cell lung cancer (NSCLC), or recurrent metastatic colorectal or breast cancer were eligible for study participation. Additionally, study participants needed to be able and willing to administer daily subcutaneous injections of mistletoe by themselves or with assistance.

2.4. Study Design and Outcomes. The objective of this two stage, dose escalation phase I clinical trial was to observe 
the safety of the combination of gemcitabine and subcutaneously injected mistletoe extract in a population with advanced solid cancers and limited treatment options.

The study design, and rationale for this two agent, dose escalation paradigm, is published elsewhere [43]. In brief, in stage I, a fixed dose of gemcitabine $\left(750 \mathrm{mg} / \mathrm{m}^{2}\right)$ was administered intravenously on day 1 and day 8 of a 3-week cycle with an escalating mistletoe dose $(1 \mathrm{mg}, 5 \mathrm{mg}, 10 \mathrm{mg}, 20 \mathrm{mg}$, $50 \mathrm{mg}, 100 \mathrm{mg}, 200 \mathrm{mg}$, and $250 \mathrm{mg} /$ day subcutaneously). As the manufacturer recommends mistletoe dosing from 50 to $200 \mathrm{mg}$, this dosing covered a range from $20 \%$ to $125 \%$ of the manufacturer recommended dose, which was considered a reasonable dosing range in a drug where there is precedence for clinical use and there are no prospective dosing data in combination with GEM. In stage II, a fixed mistletoe daily dose (as determined in stage I) was administered with gemcitabine in $20 \%$ dose increments per dose level $(900,1080$, 1380 , and $1560 \mathrm{mg} / \mathrm{m}^{2}$, resp., with the maximum dose being more than 50\%, higher than the manufacturer recommended dose of $1000 \mathrm{mg} / \mathrm{m}^{2}$ ) [43]. This stage of the study examined whether participants' ability to tolerate gemcitabine would be differentially affected by concurrently administered mistletoe injections. Enrollment of 3 patients per dose level was planned. Grade 3 nonhematologic and grade 4 hematologic events were considered dose limiting toxicities (DLT). If three patients enrolled in a dose level successfully completed three cycles of the gemcitabine-mistletoe regimen with no DLT, then subsequently enrolled patients were assigned to the next higher dosage level. However, if 1 DLT occurred, an additional $1-3$ patients were added to the cohort at that dose level for a maximum of 6 patients per dose level. The occurrence of 2 DLTs in one dosage level was considered to represent the maximum tolerated dose (MTD).

Primary study outcomes were the MTD and DLT of the combination regimen and the plasma gemcitabine pharmacokinetics alone and in combination with mistletoe extract. Secondary study outcomes were neutrophil count recovery, the stimulation of selected plasma cytokine levels (IL-6, IL-12, IFN $\gamma$, and TNF- $\alpha$ ), the time to production and the circulating plasma concentrations of mistletoe lectin-1 (ML1) and mistletoe lectin-3 (ML-3) antibodies, measured as IgG1-4 subclasses, and tumor response.

2.5. Participants and Data Collection Procedures. Enrolled participants were evaluated and treated in the hematologyoncology clinic at the National Naval Medical Center by the study investigators and NCI fellows. Prior to signing informed consent, the study investigators informed the participants about the purpose and methods of the study and explained where the study was in terms of stage and dose escalation. Once enrolled on-study, one of the study investigators instructed the study participant and family members on how to administer the daily subcutaneous mistletoe injections, with special attention to rotating the sites of injection and avoiding reinjection in the same area. Each participant (or family member) demonstrated successful subcutaneous administration of the mistletoe extract and was supplied with study supplies (i.e., sterile syringes, alcohol swabs, and sharps containers). Participants were informed that localized skin reactions, including discomfort at the injection site, redness, and itching, were commonly reported and were advised to inform the study staff if any skin reactions or other adverse events occurred.

Laboratory values were monitored twice a week, and clinical on-study evaluations were performed every cycle. CT scans were performed at baseline, and every 3 cycles. Adverse events were monitored weekly by the study investigators using ToxGrade, a software program designed for this study using the Common Terminology Criteria for Adverse Events (CTCAEv3) guidelines. Study data were tracked in a database monitored by the EMMES Corporation (Rockville, MD, USA). Independent study monitoring was provided by EMMES and KAI (both in Rockville, MD, USA).

2.6. Analytic Plan. The primary aim of this phase I study was to investigate the safety and toxicity of the mistletoe/GEM treatment regimen. As such, adverse events (any clinical event while on-study, considered related to mistletoe or gemcitabine based on published effects of the respective agents [44] rated as not related, possibly related, likely related, or definitely related), number of dose limiting toxicities, and clinical response (defined as progressive/stable disease or partial response at the time patients as assessed every 3 cycles and/or when patients were taken off of the study at disease progression, using RECIST criteria) are reported with corresponding descriptive statistics for the 44 study participants.

Secondary analyses included used Kaplan Meier [45] to assess time from study enrollment to death. Progression free survival and time to progression were initially considered but were difficult quantities to assess due to the lack of precise measurement of progression and assessment bias even when a rigorous definition is used (U.S. Food and Drug Administration CDER and CBER. Guidance for Industry Clinical Trial Endpoints for the Approval of Cancer Drugs and Biologics http://www.fda.gov/downloads/Drugs/GuidanceComplianceRegulatoryInformation/Guidances/ucm071590. pdf May 2007), and as such, time to disease progression analyses are not included in this paper.

An exploratory aim of the study was to examine potential trends of mistletoe and gemcitabine escalation on immune functioning. The a priori hypothesis was that ANC values would increase over the course of treatment; however, each group to be assessed had a small sample size. The JonckheereTerpstra trend test [46] was used to examine absolute neutrophil count (ANC) trends across time and across varying levels of gemcitabine and mistletoe treatments. This nonparametric statistical approach is similar to a Kruskal-Wallis test and has more power than the Kruskal-Wallis when there is $a$ priori ordering of the populations from which the samples are drawn.

Pharmokinetics analyses used area under the curve analyses and plasma concentrations $(\mathrm{CP}, \mathrm{nmol} / \mathrm{mL})$ from 20 minutes to 25 minutes following the infusion, comparing between cycle 1 (gemcitabine alone) and cycle 3 (gemcitabine plus mistletoe) using a Wilcoxon signed rank test. 


\section{Results}

A total of 44 study participants were enrolled on this study; twenty patients were treated in stage I (mistletoe dose escalation phase) and 24 in stage II (gemcitabine dose escalation phase). The study population's demographic information is presented in Table 1(a). All patients had stage IV disease; the majority had received previous chemo-, hormonal, immunological, or radiation therapy, and $23 \%$ were chemotherapynaïve. Patients' disease characteristics are listed in Table 1(b).

3.1. Adverse Events. A total of 706 discrete hematologic adverse events (AEs) were documented, occurring in 95\% of study participants (Table $2(\mathrm{a})$ ). The most common were low lymphocyte counts (for example, lymphopenia) ( $n=200$ events), anemia ( $n=158)$, leukopenia (e.g., total WBC count) $(n=149)$, thrombocytopenia $(n=100)$, and neutropenia (e.g., low granulocyte or absolute neutrophil count) ( $n=$ 99). The majority (85\%) of observed hematologic AEs were grade 1-2, 104 grade 3 (15\%) and five grade 4 toxicities were observed. The grade 4 AEs included 1 neutropenia event (defined as an ANC < 500), 2 thrombocytopenia events (defined as platelet count $<25,000$ ), and 2 lymphopenia events. A total of 570 nonhematologic AEs were recorded. The most common were hyperglycemia and hypoalbuminemia, followed by almost equal numbers of nausea and fatigue (Table 2(b)).

Nonneutropenic fever and flu-like syndrome, which have been previously described with mistletoe treatment and are also known AEs associated with gemcitabine, were observed in 24 of 44 (55\%) patients. More patients experienced these symptoms in stage II of the study $(15 / 24)$ than in stage I $(9 / 20)$. Only one grade 3 febrile event was observed during stage II, all other events were grade 2 or less.

3.2. Mistletoe-Related Adverse Events. Mistletoe-related nonhematologic adverse events are represented in Table 3. A total of 112 adverse events were attributed to mistletoe treatment. The most common AEs attributed to mistletoe treatment were injection site reactions (42 events), localized induration (20 events), grade 1-2 nonneutropenic fever (22 events), and grade 1-2 flu-like symptoms (10 events). All of these AEs were expected as they had been documented as known mistletoerelated AEs in the Investigators' Brochure. Seventy-five events were grade 1 , thirty-five were grade 2 , and two events were grade 3 . The two grade 3 events were cellulitis at the mistletoe injection site.

3.3. Gemcitabine-Related Adverse Events. A total of 473 hematologic AEs at least possibly related to gemcitabine were documented. Most commonly occurring number of events were leukopenia, thrombocytopenia, neutropenia, and anemia, which is consistent with the previously published data. Thirty patients developed a low WBC, and 28 patients developed thrombocytopenia. $30 \%$ of the low WBC events and close to $10 \%$ of the thrombocytopenic events were grade 3 .
A total of 249 nonhematologic events were attributed at least possibly to gemcitabine. The most common were nausea $(n=47)$ and vomiting $(n=31)$, followed by liver enzyme elevation (elevated AST $n=25$; elevated ALT $n=20$ ), nonneutropenic fever $(n=21)$, and fatigue $(n=19)$. Thirteen grade 3 events were recorded, most commonly vomiting $(n=$ $3)$ and fatigue $(n=2)$.

3.4. Maximum Tolerated Dose and Dose Limiting Toxicities. Five dose limiting toxicities (DLTs) were observed (Table 4). One study participant experienced grade 4 neutropenia at dose level 6 (mistletoe $250 \mathrm{mg} /$ gemcitabine $900 \mathrm{mg} / \mathrm{m}^{2}$ ). An additional three participants enrolled onto this dose level did not subsequently experience a DLT. One study participant experienced grade 4 thrombocytopenia at dose level 7 (mistletoe $250 \mathrm{mg} /$ gemcitabine $1180 \mathrm{mg} / \mathrm{m}^{2}$ ); three subsequent participants enrolled at this dose level did not experience a DLT. Three study participants experienced individual DLTs at dose level 9 (gemcitabine $1560 \mathrm{mg} / \mathrm{m}^{2}$ with $250 \mathrm{mg}$ daily of mistletoe). These included grade 3 cellulitis at the mistletoe injection site, grade 4 acute renal failure, and grade 4 neutropenia. As per the protocol's study design, one dose level below the dose level at which 3 DLTs were reached was defined as the maximum tolerated dose. Thus, we achieved the MTD at dose level 8 (gemcitabine $1380 \mathrm{mg} / \mathrm{m}^{2}$ and mistletoe $250 \mathrm{mg}$ ).

3.5. Pharmacokinetics of Gemcitabine. Plasma concentrations of gemcitabine from patients treated during stage I were measured in nmol/mL. Fifteen of 20 patients treated in stage I had plasma samples obtained for analysis. Twelve patients had paired samples obtained during cycle 1 (without mistletoe) and cycle 3 (with mistletoe).

The addition of mistletoe did not affect gemcitabine pharmacokinetics as measured during cycle 3 (cycle 3, day 8 of gemcitabine/mistletoe combination) compared to cycle 1 of treatment (gemcitabine alone on day 1 of treatment before mistletoe was added on day $8, P$ values ranging from 0.47 to 0.97; Table 5).

3.6. Best Clinical Response to Treatment. Figure 1(a) shows the best overall response. Of the 44 enrolled study patients, 33, completed at least 3 cycles of therapy. Of these 33, six percent $(n=2)$ had a partial response, $42 \%(n=14)$ had stable disease, and $43 \%(n=14)$ progressed on treatment. Nine percent $(n=3)$ were not evaluable for response.

3.7. Best Clinical Response according to Diagnosis. Both partial responses were observed in patients with pancreatic cancer. Three of 4 evaluable patients with NSCLC had stable disease, and 5/11 patients with breast cancer had stable disease (Figure 1(b)). Only 1 out of 8 patients with colorectal cancer had stable disease.

3.8. Survival Analyses. Of the 44 study participants, three participants died on study, 10 participants requested to 
TAble 1: (a) Study population demographics. (b) Prior treatment by disease type* .

(a)

\begin{tabular}{|c|c|c|c|c|}
\hline & Stage I $(n)$ & Stage II $(n)$ & Total $(n)$ & Total (\%) \\
\hline Number enrolled & 20 & 24 & 44 & - \\
\hline \multicolumn{5}{|l|}{ Age (years) } \\
\hline Mean & 55.0 & 55.1 & 55.1 & - \\
\hline Range & $29-81$ & $29-76$ & $29-81$ & - \\
\hline \multicolumn{5}{|l|}{ Gender } \\
\hline Male & 10 & 13 & 23 & $52 \%$ \\
\hline Female & 10 & 11 & 21 & $48 \%$ \\
\hline \multicolumn{5}{|l|}{ Race } \\
\hline White & 17 & 19 & 36 & $82 \%$ \\
\hline Black & 2 & 2 & 4 & $9 \%$ \\
\hline Asian & 0 & 3 & 3 & $7 \%$ \\
\hline \multicolumn{5}{|l|}{ Ethnicity } \\
\hline Not Hispanic & 17 & 24 & 41 & $93 \%$ \\
\hline Hispanic & 3 & 0 & 3 & $7 \%$ \\
\hline \multicolumn{5}{|l|}{ Cancer diagnosis } \\
\hline Colorectal & 4 & 13 & 17 & $39 \%$ \\
\hline Breast & 6 & 6 & 12 & $27 \%$ \\
\hline Pancreatic & 6 & 4 & 10 & $23 \%$ \\
\hline Lung & 4 & 1 & 5 & $11 \%$ \\
\hline \multicolumn{5}{|l|}{ Disease stage } \\
\hline IV & 20 & 24 & 44 & $100 \%$ \\
\hline
\end{tabular}

(b)

\begin{tabular}{|c|c|c|c|c|c|c|c|}
\hline Disease type & $\begin{array}{l}\text { No prior } \\
\text { treatment }\end{array}$ & $\begin{array}{l}\text { Chemotherapy } \\
\text { only }\end{array}$ & Radiation only & $\begin{array}{l}\text { Chemotherapy } \\
\text { and radiation }\end{array}$ & $\begin{array}{l}\text { Chemotherapy } \\
\text { and surgery }\end{array}$ & $\begin{array}{l}\text { Chemotherapy, } \\
\text { surgery, and } \\
\text { radiation }\end{array}$ & Total \\
\hline Colorectal & 0 & 4 & 0 & 1 & 8 & 4 & 17 \\
\hline Breast & 0 & 1 & 0 & 0 & 1 & 10 & 12 \\
\hline Pancreatic & 9 & 0 & 0 & 1 & 0 & 0 & 10 \\
\hline Lung & 1 & 1 & 1 & 2 & 0 & 0 & 5 \\
\hline Total $(n / \%)$ & $10(22.7 \%)$ & $6(13.6 \%)$ & $1(2.3 \%)$ & $4(9.1 \%)$ & $9(20.5 \%)$ & $14(31.8 \%)$ & 44 \\
\hline
\end{tabular}

${ }^{*}$ No study participants were treated solely with surgery or with surgery plus radiation only.

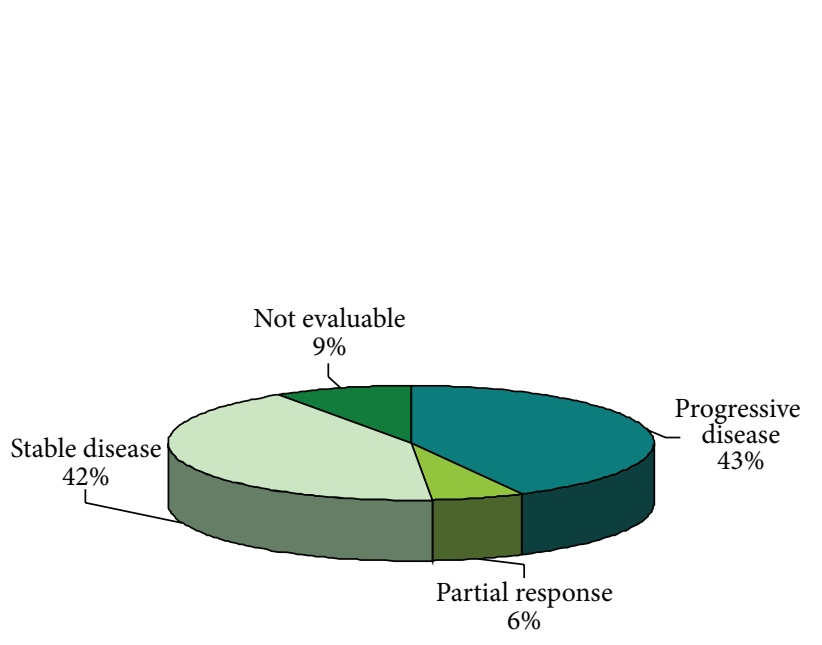

(a)

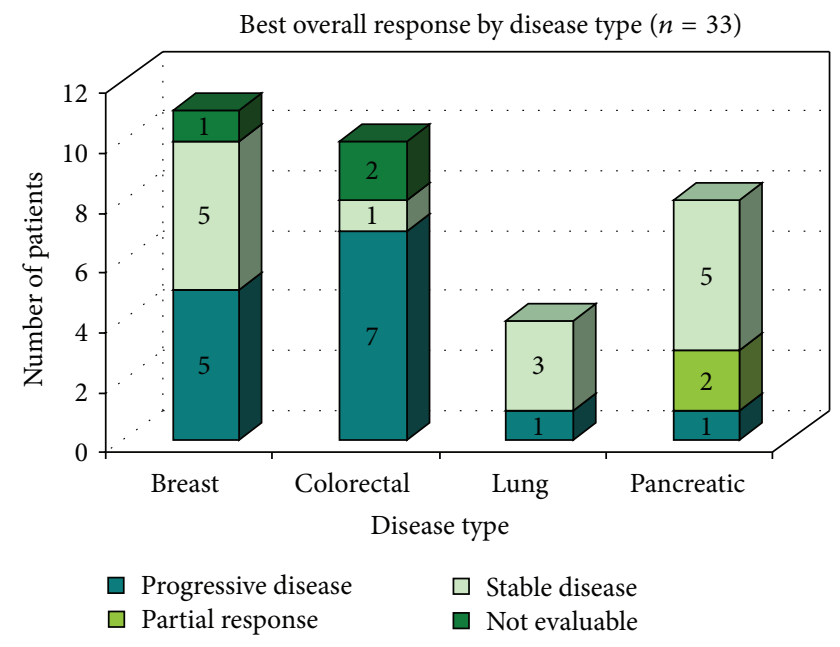

(b)

FIGURE 1: (a) Best clinical response and (b) best overall response by diagnosis. 
TABLE 2: (a) Overall hematologic CTCAE adverse events $(n=44)$. (b) Most common nonhematologic CTCAE adverse events $(n=44)$.

(a)

\begin{tabular}{|c|c|c|c|c|c|c|c|c|c|c|}
\hline \multirow{2}{*}{$\begin{array}{l}\text { Hematologic } \\
\text { adverse events }\end{array}$} & \multicolumn{4}{|c|}{$\begin{array}{l}\text { Number of events (possibly multiple } \\
\text { events from same participant) }\end{array}$} & \multirow[b]{2}{*}{ Total } & \multirow{2}{*}{$\begin{array}{c}\text { Number of } \\
\text { participants } \\
\text { experiencing } \\
\text { (multiple) events }\end{array}$} & \multicolumn{4}{|c|}{$\begin{array}{l}\text { Number of participants (with most } \\
\text { severe event if there are multiple) }\end{array}$} \\
\hline & Grade 1 & Grade 2 & Grade 3 & Grade 4 & & & Grade 1 & Grade 2 & Grade 3 & Grade 4 \\
\hline Lymphopenia & 42 & 105 & 51 & 2 & 200 & 34 & & 15 & 17 & 2 \\
\hline Anemia & 85 & 61 & 12 & & 158 & 41 & 13 & 22 & 6 & \\
\hline $\begin{array}{l}\text { Leukopenia } \\
\text { (Total WBC) }\end{array}$ & 83 & 50 & 16 & & 149 & 30 & 8 & 12 & 10 & \\
\hline Thrombocytopenia & 78 & 13 & 7 & 2 & 100 & 29 & 20 & 4 & 3 & 2 \\
\hline $\begin{array}{l}\text { Neutropenia } \\
\text { (ANC/AGC) }\end{array}$ & 41 & 39 & 18 & 1 & 99 & 26 & 4 & 11 & 10 & 1 \\
\hline $\begin{array}{l}\text { Total hematologic } \\
\text { AEs }\end{array}$ & 329 & 268 & 104 & 5 & 706 & & & & & \\
\hline
\end{tabular}

(b)

\begin{tabular}{|c|c|c|c|c|c|c|c|c|c|c|}
\hline \multirow[t]{2}{*}{$\begin{array}{l}\text { Nonhematologic } \\
\text { adverse events }\end{array}$} & \multicolumn{4}{|c|}{$\begin{array}{c}\text { Number of events (possibly multiple } \\
\text { events from same participant) }\end{array}$} & \multirow[b]{2}{*}{ Total } & \multirow{2}{*}{$\begin{array}{c}\text { Number of } \\
\text { participants } \\
\text { experiencing } \\
\text { (multiple) events }\end{array}$} & \multicolumn{4}{|c|}{$\begin{array}{l}\text { Number of participants (with most } \\
\text { severe event if there are multiple) }\end{array}$} \\
\hline & Grade 1 & Grade 2 & Grade 3 & Grade 4 & & & Grade 1 & Grade 2 & Grade 3 & Grade 4 \\
\hline Hyperglycemia & 81 & 35 & 8 & & 124 & 34 & 17 & 12 & 5 & \\
\hline Hypoalbuminemia & 53 & 38 & 2 & & 93 & 29 & 11 & 16 & 2 & \\
\hline Hypocalcemia & 59 & 19 & 1 & & 79 & 33 & 20 & 12 & 1 & \\
\hline Hyponatremia & 50 & 0 & 9 & 1 & 60 & 29 & 22 & 0 & 6 & 1 \\
\hline $\begin{array}{l}\text { Elevated AST, } \\
\text { SGOT }\end{array}$ & 42 & 13 & 2 & & 57 & 30 & 20 & 8 & 2 & \\
\hline $\begin{array}{l}\text { Elevated ALP, } \\
\text { ALKP }\end{array}$ & 29 & 22 & 5 & & 56 & 25 & 10 & 10 & 5 & \\
\hline Nausea & 27 & 23 & 1 & & 51 & 24 & 9 & 14 & 1 & \\
\hline Fatigue & 20 & 25 & 5 & & 50 & 29 & 7 & 17 & 5 & \\
\hline $\begin{array}{l}\text { Total: most } \\
\text { commonly } \\
\text { occurring } \\
\text { nonheme AEs }\end{array}$ & 361 & 175 & 33 & 1 & 570 & & 116 & 89 & 27 & 1 \\
\hline $\begin{array}{l}\text { Total: nonheme } \\
\text { AEs (overall) }\end{array}$ & 751 & 398 & 85 & 6 & 1243 & & & & & \\
\hline
\end{tabular}

terminate the study, 23 participants progressed while on study, one terminated the study due to a dose limiting toxicity, 6 left due to complicating disease issues which may be tied to progression, and one voluntarily withdrew. An attempt was made to follow study subjects once they terminated study treatment until death. At the study's last attempt to contact former participants, three were still alive and five others were lost to followup. A Kaplan Meier curve was used to illustrate time to death in Figure 2. The median time to death of any cause was approximately 200 days.

3.9. Jonckheere-Terpstra Trend Test Results for ANC Values across Increasing Dose Levels. We prospectively followed ANC nadir and ANC maximum as one of the study outcomes, hypothesizing that the ANC may be influenced by mistletoe exposure. ANC values showed a trend for increase between baseline and cycle 2 in stage I $(P=0.06)$. When ANC maximum was measured, there was a significant trend $(P=$ 0.034) for the maximum ANC level achieved in stage II during cycle 1 . However, if patients were eliminated based on dexamethasone exposure, the trend for stage I diminished $(P=0.092)$ but was maintained for cycle 1 ANC maximum during stage II $(P=0.017)$.

3.10. Development of Mistletoe Lectin $3 \mathrm{IgG}$ Antibodies and Cytokine Release. Helixor A extract is low in ML-1 and high in ML-3 content. Therefore, ML-3 content was followed. All study patients eventually developed mistletoe lectin 3 IgG antibodies. The formation of antibodies was higher at increasing doses of mistletoe.

For stage II, when all patients were exposed to the same mistletoe regimen with increasing doses of gemcitabine, 
TABLE 3: Nonhematologic CTCAE adverse events at least possibly related to mistletoe $(n=44)$.

\begin{tabular}{|c|c|c|c|c|c|c|c|c|}
\hline \multirow{2}{*}{$\begin{array}{l}\text { Nonhematologic adverse } \\
\text { events }\end{array}$} & \multicolumn{4}{|c|}{$\begin{array}{c}\text { Number of events (possibly multiple } \\
\text { same events from participant) }\end{array}$} & \multirow{2}{*}{$\begin{array}{c}\text { Number of participants } \\
\text { experiencing (multiple) } \\
\text { events }\end{array}$} & \multicolumn{3}{|c|}{$\begin{array}{l}\text { Number of participants (with most } \\
\text { severe event if there are multiple) }\end{array}$} \\
\hline & Grade 1 & Grade 2 & Grade 3 & Total & & Grade 1 & Grade 2 & Grade 3 \\
\hline Injection site reaction & 30 & 12 & & 42 & 26 & 14 & 12 & \\
\hline $\begin{array}{l}\text { Fever (in the absence of } \\
\text { neutropenia) }\end{array}$ & 18 & 4 & & 22 & 14 & 11 & 3 & \\
\hline $\begin{array}{l}\text { Induration/fibrosis skin } \\
\text { and subcutaneous tissue }\end{array}$ & 13 & 7 & & 20 & 15 & 8 & 7 & \\
\hline Flu-like syndrome & 6 & 4 & & 10 & 9 & 5 & 4 & \\
\hline Pruritus & 3 & 1 & & 4 & 3 & 2 & 1 & \\
\hline $\begin{array}{l}\text { Cellulitis (with normal } \\
\text { ANC or grade } 1 \text { or } 2 \text { ANC) }\end{array}$ & & 1 & 1 & 2 & 2 & & 1 & 1 \\
\hline $\begin{array}{l}\text { Allergic } \\
\text { reaction/hypersensitivity }\end{array}$ & & 1 & & 1 & 1 & & 1 & \\
\hline $\begin{array}{l}\text { Dermatology skin } \\
\text { reaction-NOS }\end{array}$ & & 1 & & 1 & 1 & & 1 & \\
\hline $\begin{array}{l}\text { Cellulitis with unknown } \\
\text { ANC }\end{array}$ & & & 1 & 1 & 1 & & & 1 \\
\hline Lymphatics-NOS & 1 & & & 1 & 1 & 1 & & \\
\hline Lymphedema & & 1 & & 1 & 1 & & 1 & \\
\hline Myalgia NOS & 1 & & & 1 & 1 & 1 & & \\
\hline Pain-joint & & 1 & & 1 & 1 & & 1 & \\
\hline Pain-skin & 1 & & & 1 & 1 & 1 & & \\
\hline Phlebitis & & 1 & & 1 & 1 & & 1 & \\
\hline $\begin{array}{l}\text { Rash: erythema } \\
\text { multiforme }\end{array}$ & & 1 & & 1 & 1 & & 1 & \\
\hline Rigors/chills & 1 & & & 1 & 1 & 1 & & \\
\hline Total nonheme AEs & 75 & 35 & 2 & 112 & & & & \\
\hline
\end{tabular}

NOS: not otherwise specified.

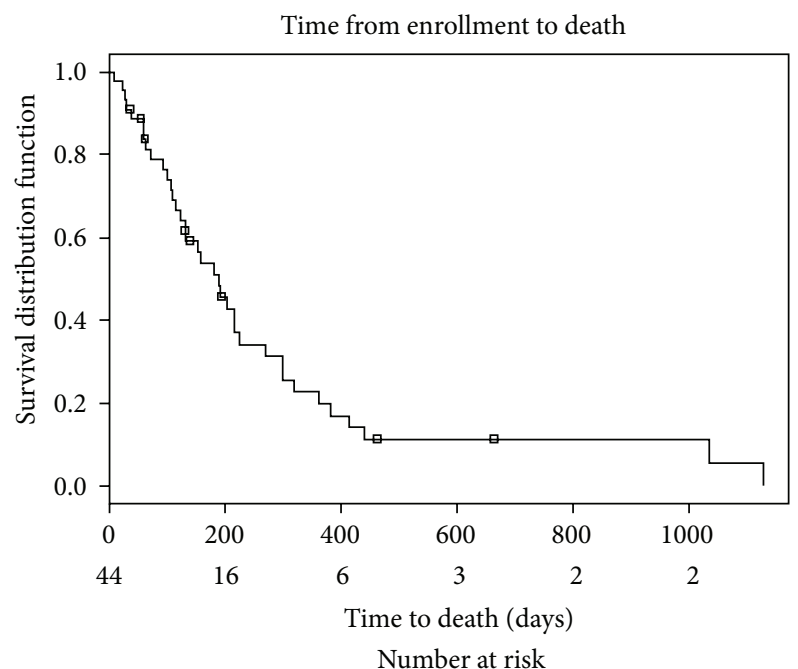

FIGURE 2: Time from enrollment to death.

only IgG3 antibody levels increased with increasing doses of gemcitabine (data not shown). Cytokines were minimally affected by this combination regimen.

\section{Discussion}

To our knowledge, this is the first reported dose escalation study of a whole mistletoe extract combined with single agent gemcitabine in patients with advanced solid cancers. As per the manufacturer's information [44], nonfebrile neutropenia as a function of dose in gemcitabine was observed in $63 \%$ (19\% grade 3, 6\% grade 4). Thrombocytopenia occurred in $24 \%$ ( $4 \%$ grade $3,1 \%$ grade 4$)$. Gemzar as a single agent was administered at doses between $800 \mathrm{mg} / \mathrm{m}^{2}$ and $1250 \mathrm{mg} / \mathrm{m}^{2}$ over 30 minutes intravenously, once weekly, in 979 patients with a variety of malignancies.

We observed 30\% grade 3 neutropenia and 10\% grade 3 thrombocytopenia, while single agent gemcitabine testing has resulted in $19 \%$ grade 3 nonfebrile neutropenia and $4 \%$ grade 3 thrombocytopenia [44]. Thirty-seven percent of patients experienced nonneutropenic fever, while single agent gemcitabine was associated with $41 \%$ fever. There was no documented incidence of febrile neutropenia for the combination regimen. Flu-like symptoms occurred in $18 \%$ of patients.

The hematologic toxicity profile of the mistletoe/gemcitabine combination and febrile reactions in this study were similar to single agent gemcitabine [44]. The addition of 
TABLE 4: Dose limiting toxicities by dose level.

\begin{tabular}{|c|c|c|c|c|c|c|}
\hline \multicolumn{3}{|c|}{ Stage I (fixed GEM dose of $750 \mathrm{mg} / \mathrm{m}^{2}$ ) } & \multicolumn{4}{|c|}{ Stage II (fixed mistletoe dose, established in stage 1) } \\
\hline Level & $n$ & DLT & Level/dosage & $n$ & DLT & $\begin{array}{l}\text { Action taken per } \\
\text { protocol }\end{array}$ \\
\hline $\begin{array}{l}\text { (1) } \\
\text { (escalating daily } \\
\text { mistletoe injections, } \\
\text { reaching: } 20 \mathrm{mg} / \text { day) }\end{array}$ & 3 & None & 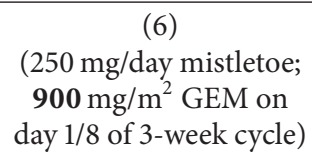 & 7 & Grade 4 neutropenia & $\begin{array}{c}\text { Dose reduced; enrolled } 3 \\
\text { more patients at this } \\
\text { dose level }\end{array}$ \\
\hline $\begin{array}{l}\text { (2) } \\
\text { (escalating daily } \\
\text { mistletoe injections, } \\
\text { reaching: } 50 \mathrm{mg} / \text { day) }\end{array}$ & 3 & None & $\begin{array}{c}(7) \\
(250 \mathrm{mg} / \text { day mistletoe; } \\
\mathbf{1 0 8 0} \mathrm{mg} / \mathrm{m}^{2} \text { GEM on } \\
\text { day } 1 / 8 \text { of } 3 \text {-week cycle) }\end{array}$ & 7 & $\begin{array}{c}\text { Grade } 4 \\
\text { thrombocytopenia }\end{array}$ & $\begin{array}{c}\text { Dose reduced; enrolled } 3 \\
\text { more patients at this } \\
\text { dose level }\end{array}$ \\
\hline $\begin{array}{l}\text { (3) } \\
\text { (escalating daily } \\
\text { mistletoe injections, } \\
\text { reaching: } 100 \mathrm{mg} / \text { day) }\end{array}$ & 3 & None & $\begin{array}{c}(8)^{*} \\
(250 \mathrm{mg} / \text { day mistletoe; } \\
\mathbf{1 3 8 0} \mathrm{mg} / \mathrm{m}^{2} \text { GEM on } \\
\text { day } 1 / 8 \text { of } 3 \text {-week cycle) }\end{array}$ & 6 & None & N/A \\
\hline $\begin{array}{l}\text { (escalating daily } \\
\text { mistletoe injections, } \\
\text { reaching: } 200 \mathrm{mg} / \text { day) }\end{array}$ & 6 & None & $\begin{array}{c}(9) \\
(250 \mathrm{mg} / \text { day mistletoe; } \\
\mathbf{1 5 6 0} \mathrm{mg} / \mathrm{m}^{2} \text { GEM on } \\
\text { day } 1 / 8 \text { of } 3 \text {-week cycle })\end{array}$ & 4 & $\begin{array}{l}\text { Grade } 3 \text { cellulitis }{ }^{\mathrm{a}} \text {; } \\
\text { grade } 4 \text { acute renal } \\
\text { failure }^{\mathrm{b}} \text {; grade } 4: \\
\text { thrombocytopenia }^{\mathrm{c}}\end{array}$ & $\begin{array}{l}{ }^{\mathrm{a}} \text { Mistletoe therapy } \\
\text { withheld; patient } \\
\text { rechallenged and } \\
\text { developed } \\
\text { hypersensitivity } \\
\text { reaction. Mistletoe } \\
\text { discontinued; }{ }^{\mathrm{b}} \mathrm{Pt} \text {. } \\
\text { treated for renal failure } \\
\text { and subsequently } \\
\text { withdrawn from study; } \\
{ }^{\mathrm{c}} \mathrm{Pt} \text {. hospitalized } \mathrm{d} / \mathrm{t} \\
\text { other AE; Maximum } \\
\text { tolerated dose reached } \\
\text { per protocol }\end{array}$ \\
\hline $\begin{array}{l}\text { (5) } \\
\text { (escalating daily } \\
\text { mistletoe injections, } \\
\text { reaching: } 250 \mathrm{mg} / \text { day) }\end{array}$ & 5 & None & & & & \\
\hline
\end{tabular}

${ }^{*}$ Per study protocol, this level represents the maximum tolerated dose, as 3 DLT's were observed in the subsequent dose level.

TABLE 5: Pharmacokinetics of gemcitabine (cycle 1) and gemcitabine plus mistletoe (cycle 3).

\begin{tabular}{|c|c|c|c|}
\hline & $\begin{array}{c}\text { Cycle 1 } \\
\text { Median } \\
(25 \text { th } \%, 75 \text { th } \%)\end{array}$ & $\begin{array}{c}\text { Cycle } 3 \\
\text { Median } \\
(25 \text { th } \%, 75 \text { th } \%) \\
\end{array}$ & $\begin{array}{c}P \text { value } \\
\text { Signed rank test }\end{array}$ \\
\hline $\begin{array}{l}\text { Gemcitabine } \\
\text { AUC }(\min * \mathrm{nmol} / \mathrm{mL})\end{array}$ & $\begin{array}{c}664 \\
(514,870)\end{array}$ & $\begin{array}{c}670 \\
(625,851)\end{array}$ & 0.97 \\
\hline $\begin{array}{l}\text { Gemcitabine } \\
\text { Average } \mathrm{Cp}(\mathrm{nmol} / \mathrm{mL})\end{array}$ & $\begin{array}{c}47.7 \\
(42.7,64.6)\end{array}$ & $\begin{array}{c}49.7 \\
(45.7,53.8)\end{array}$ & 0.85 \\
\hline
\end{tabular}

mistletoe did not exacerbate hematologic gemcitabine toxicity. Interestingly, there was a trend $(P=0.06)$ towards increased ANC nadir during the first 3 weeks of initiation of mistletoe and of ANC maximum during the first 6 weeks as a function of mistletoe dose $(P=0.034)$. Others have claimed that mistletoe may boost chemotherapy tolerance, but published data on dosing and mistletoe schedule are lacking, while these were collected in detail in this study.

Flu-like symptoms may be more common when mistletoe is added to gemcitabine. We observed febrile and flu-like reactions attributable to mistletoe across the entire mistletoe dosing spectrum that did not seem to be dose dependent.

The addition of mistletoe did not affect the pharmacokinetics of gemcitabine at any of the mistletoe dose levels tested, suggesting that mistletoe can be added to gemcitabine without concern about adversely affecting gemcitabine's pharmacokinetic profile. The MTD for the gemcitabine/mistletoe combination in this study was gemcitabine $1380 \mathrm{mg} / \mathrm{m}^{2}$ given weekly on day one and eight of a three-week cycle with 
mistletoe $250 \mathrm{mg}$ s.c. daily. As per the manufacturer recommendations, gemcitabine is commonly dosed at $1000 \mathrm{mg}$ i.v. weekly for three weeks on a 28-day cycle. In our study a higher dose was tolerated.

Stimulatory effects of mistletoe on neutrophils and lymphocytes have been reported in vitro as well as in patients. We observed a mistletoe dose-dependent trend towards increased absolute neutrophil count ANC nadir during cycle 1 and ANC maximum during cycle 2. None of the study patients developed febrile neutropenia even at the highest gemcitabine dose of $1650 \mathrm{mg} / \mathrm{m}^{2}$. As this study employed a dose escalation scheme in a diverse group of patients with advanced cancer, many of whom were heavily pretreated, this observation would have to be verified and confirmed in a setting of increased homogeneity of patient population and treatment regimen with a larger sample size.

There is a sizable body of literature on the effects of mistletoe on cytokine production [21]. We selected testing for IL-6, IL-12, IFN gamma, and TNF alpha based on their previously described role in tumor development and proliferation as well as existing publications of possible effects of mistletoe on the production of these cytokines. The production of these cytokines in patients with cancer however has not been studied in detail when chemotherapy was combined with mistletoe. We did not detect any consistent pattern of increased or decreased production of any of the cytokines tested.

Mistletoe lectin (ML)-3 antibody formation of the IgG type was detected in all patients by cycle 3 of therapy or 9 weeks and thus was independent of the actual mistletoe dose administered. The physiologic effect of the formation of ML antibodies is not well understood. While we did not compare participants' injections site reactions to this immunological data, we did observe injection site reactions early in treatment of all study participants. Others have reported local reactions in $87 \%$ [31]. In most studies, mistletoe is injected three times per week, while our patients injected mistletoe daily. It is thus not surprising that our study would find a higher rate of local injection site reactions. Skin reactions decreased over the course of therapy. This phenomenon may have resulted from the increasing formation of ML antibodies over time mitigating the mistletoe related injection site reactions. Febrile reactions occurred in more than onethird of the patients. It is not clear from our data that there was any relationship between the appearance of ML antibodies and febrile reactions or other toxicities. The study was not designed to yield reliable data on clinical response to the study regimen. Therefore, we are unable to determine associations between clinical response and the formation of ML antibodies or febrile reactions. Future studies may add the understanding of the physiological reactions to mistletoe therapy by connecting immunological data to changes in symptom presentation.

The finding of a partial response rate of $6 \%$ is comparable to what would be expected from single agent gemcitabine in this population of patients with advanced, mostly heavily pretreated carcinomas. The median survival from study enrollment of about 200 days is within the range of what would be expected from single agent gemcitabine. Compliance with the mistletoe regimen was high, and no episode of febrile neutropenia was observed in any of the 44 patients. The lack of episodes of febrile neutropenia in a set of heavily pretreated patients of whom almost $50 \%$ received gemcitabine doses of $1100 \mathrm{mg} / \mathrm{m}^{2}$ or higher is noteworthy, but would have to be confirmed in a larger, more homogenous cancer population.

The above results should be interpreted in light of several study limitations. First, the study sample included 4 different types of solid tumors, each of which may respond differently to GEM or mistletoe/GEM therapy. As such, the results presented herein may not extend to more homogenous groups of cancer patients. Second, the overall sample size was small $(n=44)$. As a result, the study may have been underpowered to detect significant trends for the study outcomes. Despite the majority of study outcomes remaining descriptive in nature, the statistical tests applied (e.g., survival analyses and Jonckheere-Terpstra trend test) should be interpreted in light of the small sample sizes used in each respective test. The overall small sample size precluded subgroup analyses (e.g., treatment naïve participants' response), which may be a worthwhile area for future studies to pursue. Finally, the study was not designed to examine the effectiveness of a mistletoe/GEM combination. Future work should apply double blind, randomized controlled study designs to examine.

\section{Conclusion}

The combination of mistletoe and gemcitabine was well tolerated and treatment compliance was high. The MTD was gemcitabine $1380 \mathrm{mg} / \mathrm{m}^{2}$ weekly on day one and eight of a 3 -week cycle combined with mistletoe $250 \mathrm{mg}$ daily. Gemcitabine pharmacokinetics were not affected by mistletoe. The lack of febrile neutropenia even at higher gemcitabine doses is noteworthy. The formation of ML antibodies is common. A consistent effect of the study regimen on the serum levels of selected cytokines could not be demonstrated. Clinical response of the combination appeared to be similar to single agent gemcitabine reported previously.

\section{Conflict of Interests}

All authors were contacted, and the possibility of conflict of interests was explored. None of the authors listed reported any conflict of interests regarding the content of this paper or investigational agents used for the research reported therein.

\section{Authors' Contribution}

Dawn B. Wallerstedt, Timothy S. Sannes, and Jamie Stagl contributed to data collection and interpretation and paper writing. All other authors also contributed to the design and funding of the study.

\section{Acknowledgments}

The authors would like to acknowledge the help and advice of Drs. Agnes Nguyenpho, FDA; Maria Merino, Laboratory of Pathology, NCI; Alex Ling, Diagnostic Imaging Department, 
Clinical Center, NIH; and Julia T. Arnold, NCCAM. They greatly appreciate the technical assistance of Howard Baldwin, NCCAM, and the support of Drs. Dieter Schlodder and Juergen Schierholz as well as Sabine Rieger from Helixor $\mathrm{GmbH}$. The authors also thank the NIH and NNMC fellows, nurses, pharmacy staff, and all the patients who made it possible to conduct this study. This research was supported, in part, by the Intramural Research Programs of the NIH, NCCAM, and NCI and was done at the Intramural Research Program of the National Center for Complementary and Alternative Medicine, National Institutes of Health. Conclusions drawn and recommendations for future directions made are the opinions of the authors and do not represent the view of the National Center for Complementary and Alternative Medicine, The Department of the Navy, Department of Defense, or the National Cancer Institute. Mistletoe extract (Helixor A) was provided by Helixor GmbH, Rosenfeld, Germany, which also supported the mistletoe lectin analyses.

\section{References}

[1] S. Elluru, J. D. van Huyen, S. Delignat et al., "Molecular mechanisms underlying the immunomodulatory effects of mistletoe (Viscum album L.) extracts Iscador," Arzneimittel-Forschung, vol. 56, no. 6, pp. 461-466, 2006.

[2] R. Steiner, Geisteswissenschaft und Medizin, Rudolf Steiner, Dornach, Switzerland, 1985.

[3] K. Hostanska, T. Hajto, G. C. Spagnoli, J. Fischer, H. Lentzen, and R. Herrman, "A plant lectin derived from Viscum album induces cytokine gene expression and protein production in cultures of human peripheral blood mononuclear cells," Natural Immunity, vol. 14, no. 5-6, pp. 295-304, 1995.

[4] G. Stein and P. A. Berg, "Non-lectin component in a fermented extract from Viscum album L, grown on pines induces proliferation of lymphocytes from healthy and allergic individuals in vitro," European Journal of Clinical Pharmacology, vol. 47, no. 1, pp. 33-38, 1994.

[5] R. Rentea, E. Lyon, and R. Hunter, "Biologic properties of Iscador: a Viscum album preparation. I. Hyperplasia of the thymic cortex and accelerated regeneration of hematopoietic cells following X-irradiation," Laboratory Investigation, vol. 44, no. 1, pp. 43-48, 1981.

[6] J. Beuth, H. L. Ko, L. Tunggal et al., “Thymocyte proliferation and maturation in response to galactoside-specific mistletoe lectin-1," In Vivo, vol. 7, no. 5, pp. 407-410, 1993.

[7] G. Kuttan, "Tumoricidal activity of mouse peritoneal macrophages treated with Viscum album extract," Immunological Investigations, vol. 22, no. 6-7, pp. 431-440, 1993.

[8] K. Hamprecht, R. Handgretinger, W. Voetsch, and F. A. Anderer, "Mediation of human NK-activity by components in extracts of Viscum album," International Journal of Immunopharmacology, vol. 9, no. 2, pp. 199-209, 1987.

[9] T. Hajto and C. Lanzrein, "Natural killer and antibodydependent cell-mediated cytotoxicity activities and large granular lymphocyte frequencies in Viscum album-treated breast cancer patients," Oncology, vol. 43, no. 2, pp. 93-97, 1986.

[10] A. Bussing, "Mistletoe therapy and immunological research," Anti-Cancer Drugs, vol. 8, no. 1, p. S65, 1997.

[11] G. M. Stein and P. A. Berg, "Mistletoe extract-induced effects on immunocompetent cells: in vitro studies," Anti-Cancer Drugs, vol. 8, no. 1, pp. S39-S42, 1997.
[12] H. J. Gabius, S. André, H. Kaltner, H. C. Siebert, C. W. von der Lieth, and S. Gabius, "The mistletoe myth: claims, reality and provable perspectives," Zeitschrift fur Arztliche Fortbildung, vol. 90, no. 2, pp. 103-110, 1996.

[13] H. Franz, "Mistletoe lectins and their A and B chains," Oncology, vol. 43, no. 1, pp. 23-34, 1986.

[14] U. Elsasser-Beile, M. Voss, R. Schuhle, and U. Wetterauer, "Biological effects of natural and recombinant mistletoe lectin and an aqueous mistletoe extract on human monocytes and lymphocytes in vitro," Journal of Clinical Laboratory Analysis, vol. 14, no. 6, pp. 255-259, 2000.

[15] U. Elsässer-Beile, S. Lusebrink, T. Grussenmeyer, U. Wetterauer, and W. Schultze-Seemann, "Comparison of the effects of various clinically applied mistletoe preparations on peripheral blood leukocytes," Arzneimittel-Forschung, vol. 48, no. 12, pp. 1185-1189, 1998.

[16] T. Hajto, T. Berki, L. Palinkas, F. Boldizsar, and P. Nemeth, "Investigation of the effect of mistletoe (Viscum album L.) extract Iscador on the proliferation and apoptosis of murine thymocytes," Arzneimittelforschung, vol. 56, no. 6, pp. 441-446, 2006.

[17] R. Samtleben, T. Hajto, and K. Hostanska, "Mistletoe lectins as immunostimulants (chemistry, pharmacology and clinic)," in Immunomodulatory Agents from Plants, H. Wagner, Ed., pp. 223-241, Birkhäauser, Basel, Switzerland, 1999.

[18] R. T. Lee, H. J. Gabius, and Y. C. Lee, "Ligand binding characteristics of the major mistletoe lectin," The Journal of Biological Chemistry, vol. 267, no. 33, pp. 23722-23727, 1992.

[19] G. Ribéreau-Gayon, S. Dumont, C. Muller, M. L. Jung, P. Poindron, and R. Anton, "Mistletoe lectins I, II and III induce the production of cytokines by cultured human monocytes," Cancer Letters, vol. 109, no. 1-2, pp. 33-38, 1996.

[20] T. Hajto, K. Hostanska, K. Weber et al., "Effect of a recombinant lectin, Viscum album agglutinin on the secretion of interleukin12 in cultured human peripheral blood mononuclear cells and on NK-cell-mediated cytotoxicity of rat splenocytes in vitro and in vivo," Natural Immunity, vol. 16, no. 1, pp. 34-46, 1998.

[21] T. Hajto, K. Hostanska, K. Frei, C. Rordorf, and H. J. Gabius, "Increased secretion of tumor necrosis factor $\alpha$, interleukin 1 , and interleukin 6 by human mononuclear cells exposed to $\beta$-galactoside-specific lectin from clinically applied mistletoe extract," Cancer Research, vol. 50, no. 11, pp. 3322-3326, 1990.

[22] H. O. Pae, W. G. Seo, G. S. Oh et al., "Potentiation of tumor necrosis factor- $\alpha$-induced apoptosis by mistletoe lectin," Immunopharmacology and Immunotoxicology, vol. 22, no. 4, pp. 697-709, 2000.

[23] A. Büssing, G. M. Stein, U. Pfüller, and M. Schietzel, "Induction of Fas ligand (CD95L) by the toxic mistletoe lectins in human lymphocytes," Anticancer Research, vol. 19, no. 3, pp. 1785-1790, 1999.

[24] J. Eggenschwiler, A. Patrignani, U. Wagner et al., "Gene expression profiles of different breast cancer cells compared with their responsiveness to fermented mistletoe (Viscum album L.) extracts Iscador from oak (Quercus), pine (Pinus), white fir (Abies) and apple tree (Malus) in vitro," Arzneimittel-Forschung, vol. 56, no. 6, pp. 483-496, 2006.

[25] K. Weber, U. Mengs, T. Schwarz, H. Becker, and H. Lentzen, "Stimulation of neutropoiesis by a special standardized mistletoe preparation after cyclophosphamide chemotherapy in mice," Arzneimittel-Forschung, vol. 46, no. 12, pp. 1174-1178, 1996. 
[26] A. Savoie, V. Lavastre, M. Pelletier, T. Hajto, K. Hostanska, and D. Girard, "Activation of human neutrophils by the plant lectin Viscum album agglutinin-I: modulation of de novo protein synthesis and evidence that caspases are involved in induction of apoptosis," Journal of Leukocyte Biology, vol. 68, no. 6, pp. 845-853, 2000.

[27] A. Stettin, J. L. Schultze, E. Stechemesser, and P. A. Berg, "Antimistletoe lectin antibodies are produced in patients during therapy with an aqueous mistletoe extract derived from Viscum album L. and neutralize lectin-induced cytotoxicity in vitro," Klinische Wochenschrift, vol. 68, no. 18, pp. 896-900, 1990.

[28] G. M. Stein and P. A. Berg, "Characterisation of immunological reactivity of patients with adverse effects during therapy with an aqueous mistletoe extract," European Journal of Medical Research, vol. 4, no. 5, pp. 169-177, 1999.

[29] G. M. Stein, U. Pfüller, and P. A. Berg, "Recognition of different antigens of mistletoe extracts by anti-mistletoe lectin antibodies," Cancer Letters, vol. 135, no. 2, pp. 165-170, 1999.

[30] R. W. Gorter, M. van Wely, M. Reif, and M. Stoss, “Tolerability of an extract of European mistletoe among immunocompromised and healthy individuals," Alternative Therapies in Health and Medicine, vol. 5, no. 6, pp. 37-48, 1999.

[31] R. Huber, J. Eisenbraun, B. Miletzki et al., "Pharmacokinetics of natural mistletoe lectins after subcutaneous injection," European Journal of Clinical Pharmacology, vol. 66, no. 9, pp. 889897, 2010.

[32] P. R. Bock, W. E. Friedel, J. Hanisch, M. Karasmann, and B. Schneider, "Efficacy and safety of long-term complementary treatment with standardized european mistletoe extract (Viscum album L.) in addition to the conventional adjuvant oncologic therapy in patients with primary non-metastasized mammary carcinoma/results of a multicenter, comparative, epidemiological cohort study in Germany and Switzerland," Arzneimittel-Forschung, vol. 54, no. 8, pp. 456-466, 2004.

[33] H. Matthes, W. E. Friedel, P. R. Bock, and K. S. Zanker, "Molecular mistletoe therapy: friend or foe in established anti-tumor protocols? A multicenter, controlled, retrospective pharmacoepidemiological study in pancreas cancer," Current Molecular Medicine, vol. 10, no. 4, pp. 430-439, 2010.

[34] T. Ostermann and A. Bussing, "Retrolective studies on the survival of cancer patients treated with mistletoe extracts: a meta-analysis," Explore, vol. 8, no. 5, pp. 277-281, 2012.

[35] G. S. Kienle, A. Glockmann, M. Schink, and H. Kiene, "Viscum album L. extracts in breast and gynaecological cancers: a systematic review of clinical and preclinical research," Journal of Experimental and Clinical Cancer Research, vol. 28, article 79, 2009.

[36] T. Ostermann, C. Raak, and A. Bussing, "Survival of cancer patients treated with mistletoe extract (Iscador): a systematic literature review," BMC Cancer, vol. 9, article 451, 2009.

[37] M. A. Horneber, G. Bueschel, R. Huber, K. Linde, and M. Rostock, "Mistletoe therapy in oncology," Cochrane Database of Systematic Reviews, no. 2, Article ID CD003297, 2008.

[38] G. S. Kienle and H. Kiene, "Complementary cancer therapy: a systematic review of prospective clinical trials on anthroposophic mistletoe extracts," European Journal of Medical Research, vol. 12, no. 3, pp. 103-119, 2007.

[39] R. Grossarth-Maticek, H. Kiene, S. M. Baumgartner, and R. Ziegler, "Use of iscador, an extract of European mistletoe (Viscum album), in cancer treatment: prospective nonrandomized and randomized matched-pair studies nested within a cohort study," Alternative Therapies in Health and Medicine, vol. 7, no. 3, pp. 57-76, 2001.

[40] D. Lenartz, U. Dott, J. Menzel, J. M. Schierholz, and J. Beuth, "Survival of glioma patients after complementary treatment with galactoside-specific lectin from mistletoe," Anticancer Research, vol. 20, no. 3, pp. 2073-2076, 2000.

[41] M. K. Steuer-Vogt, V. Bonkowsky, P. Ambrosch et al., "The effect of an adjuvant mistletoe treatment programme in resected head and neck cancer patients: a randomised controlled clinical trial," European Journal of Cancer, vol. 37, no. 1, pp. 23-31, 2001.

[42] G. Bar-Sela, M. Wollner, L. Hammer, A. Agbarya, E. Dudnik, and N. Haim, "Mistletoe as complementary treatment in patients with advanced non-small-cell lung cancer treated with carboplatin-based combinations: a randomised phase II study," European Journal of Cancer, vol. 49, no. 5, pp. 1058-1064, 2013.

[43] P. J. Mansky, J. Grem, D. B. Wallerstedt, B. P. Monahan, and M. R. Blackman, "Mistletoe and gemcitabine in patients with advanced cancer: a model for the phase I study of botanicals and botanical-drug interactions in cancer therapy," Integrative Cancer Therapies, vol. 2, no. 4, pp. 345-352, 2003.

[44] http://pi.lilly.com/us/gemzar.pdf.

[45] E. L. Kaplan and P. Meier, "Nonparametric estimation from incomplete observations," Journal of the American Statistical Association, vol. 53, no. 282, pp. 457-481, 1958.

[46] A. R. Jonckheere, "A distribution-free k-sample test against ordered alternatives," Biometrika, vol. 41, no. 1-2, pp. 133-145, 1954. 